\title{
Influence of Twinning Texture on the Corrosion Fatigue Behavior of Extruded Magnesium Alloys
}

\author{
Jiaqi $\mathrm{Hu}^{1} \cdot$ Qite $\mathrm{Li}^{1} \cdot$ Hong Gao ${ }^{1}$
}

Received: 18 March 2020 / Revised: 12 May 2020 / Accepted: 19 May 2020 / Published online: 14 August 2020

(c) The Chinese Society for Metals (CSM) and Springer-Verlag GmbH Germany, part of Springer Nature 2020

\begin{abstract}
Bio-magnesium alloys have received great attention due to their degradability and biocompatibility. Corrosion fatigue failure is a huge challenge in vivo for bio-magnesium alloy implants. Understanding the effects of twinning textures on the corrosion fatigue of magnesium alloys is meaningful for the applications. In the current study, pre-compression strains of $2 \%$ and $4 \%$ were carried out on extruded rods. The effects of twinning texture on the corrosion performance and corrosion fatigue resistance were investigated. The hydrogen evolution tests indicated that twinning texture enhanced the corrosion resistance of longitudinal cross section by improving uniformity of surface energy. The results of corrosion fatigue tests indicated that the differences in mechanical damage caused by twinning texture dominated the corrosion fatigue behavior under high stress amplitude. The secondary cracks of surface deteriorated the corrosion fatigue resistance of the original specimens under low stress amplitude. The compact corrosion film and the re-passivation of matrix suppressed the hydrogen induced cracking, thereby improving the corrosion fatigue resistance of the pre-compression specimens.
\end{abstract}

Keywords Magnesium alloy $\cdot$ Corrosion fatigue $\cdot$ Extension twins $\cdot$ Secondary crack

\section{Introduction}

Due to the low density, good machinability, and high specific strength, magnesium alloys have received increasing attention in numerous fields, including aerospace, automobile, and biomedical [1-3]. Especially for the application of biological implantation, Mg alloys have excellent bio-degradability, comparable mechanical properties with natural bone, and the best bio-compatibilities with human physiology [4-6]. However, in orthopedics treatment, a bio-implant inevitably suffers from cyclic loading during walking, running, or jumping [7, 8]. Under the simultaneous action of the corrosive human body fluid and the cyclic loading of human body, implants must have adequate corrosion fatigue resistance to avoid catastrophic consequences. Hence, corrosion fatigue studies of $\mathrm{Mg}$ alloys are essential to the applications.

Available online at http://link.springer.com/journal/40195.

Hong Gao

hgao@tju.edu.cn

1 School of Chemical Engineering and Technology, Tianjin University, Tianjin 300072, China
Pre-compression, as a simple and cost-effective pre-treatment method, can produce a large number of extension twins in $\mathrm{Mg}$ alloy extruded rods, resulting in a twinning texture of $c$-axis // extrusion direction (ED) $[9,10]$. Both texture orientation and extension twins affect the corrosion behavior of Mg alloys. Zou et al. [11] reported that the extension twins of $\mathrm{Mg}-\mathrm{Y}$ alloys changed the pitting potential, film formation sequence, and charge transfer resistance due to the increased surface energy of atoms. In addition, the appearance of extension twins can accelerate the formation of compact surface film, resulting in the improvement of corrosion resistance [12]. In terms of texture orientation, generally the basal plane of grains has the better corrosion resistance than the non-basal plane due to its higher atomic density and thus a lower surface energy [13, 14]. Moreover, the results of corrosion resistance are also related to the uniformity of surface energy. Wang et al. [15, 16] reported that in extruded Mg alloys the longitudinal cross section composed of basal and non-basal planes exhibited weaker corrosion resistance than the transverse cross section mainly composed of prismatic planes. Their research indicated that a surface primarily composed of similar crystal planes can suppress localized galvanic corrosion, improve the uniformity and stability of the surface oxide film. 
Mg alloys have been proven to be susceptible to environmentally assisted cracking (EAC) in corrosion environments, displaying significantly lower corrosion fatigue resistance in the modified simulated body fluids than in air $[17,18]$. It is necessary to investigate the feasible methods for improving their corrosion fatigue resistance. Wang et al. [19] reported that solution treatment decreased the corrosion attack of as-forged $\mathrm{Mg}-\mathrm{Zn}-\mathrm{Y}-\mathrm{Zr}$ alloys, thereby suppressing the influence of hydrogen embrittlement (HE) on the corrosion fatigue resistance. Jafari et al. [20] reported that the suppression of pitting corrosion at the cathodic charging effectively improved the corrosion fatigue resistance of $\mathrm{Mg}$ alloys, although more hydrogen will be introduced. Moreover, it was proved that increasing the stability of the surface film and the re-passivation kinetics was beneficial in lowering the corrosion and EAC tendency of $\mathrm{Mg}$ alloys [21, 22].

In the current study, three kinds of specimens with different pre-compression strains were prepared. Their corrosion behaviors freed from stress were investigated by hydrogen evolution tests. Then, corrosion fatigue tests were carried out to evaluate their performance differences under simultaneous action of the corrosive environment and the cyclic loading. Besides, the effect of extension twins and texture orientation on corrosion behaviors of extruded bars was discussed in detail. The mechanisms for the improvement in corrosion fatigue resistance after pre-compression treatment were also clarified.

\section{Materials and Methods}

Commercial extruded AM60 rods (nominal composition $6.0 \% \mathrm{Al}$ and $0.5 \% \mathrm{Mn}$ with $\mathrm{Mg}$ as the balance in weight percentage) of diameter $16 \mathrm{~mm}$ were used in this study, and as-received rods were marked as AR specimens. Precompression treatment was conducted on AR specimens with a constant strain rate of $3.33 \times 10^{-4} \mathrm{~s}^{-1}$. PRC2 and PRC4 denoted specimens subjected $2 \%$ and $4 \%$ compressive strains, respectively. Figure 1a shows the schematic of pre-compression specimen processing. It is obvious that the activation of extension twins results in low flow stress under the monotonic compression [9]. During the plastic flow stage, the slope of the curve remains stable, indicating that the flow in this region is always dominated by twinning [23]. Song et al. reported that for the deformation dominated by $\{10-12\}$ twinning, the contribution of slip to the plastic strain is very limited, resulting in low dislocation storage and residual stress in the matrix [24].

An MTS-370 servo-hydraulic test system was employed for mechanical tests. Since the strain of specimens was hard to obtain in a corrosive environment, online corrosion fatigue tests were controlled by stress, using a triangular waveform at a $10 \mathrm{~Hz}$ frequency. Figure $1 \mathrm{~b}$ shows the schematic of corrosion fatigue experimental setup. The corrosion fatigue specimen with gauge diameter $6 \mathrm{~mm}$ and gauge length $15 \mathrm{~mm}$ was set in a corrosion chamber, which contained circulating phosphate buffer saline (PBS) solution $\left(8 \mathrm{~g} / \mathrm{L} \mathrm{NaCl}, 0.2 \mathrm{~g} / \mathrm{L} \mathrm{KCl}, 1.44 \mathrm{~g} / \mathrm{L} \mathrm{Na}_{2} \mathrm{HPO}_{4}\right.$ and $0.24 \mathrm{~g} / \mathrm{L}$ $\left.\mathrm{KH}_{2} \mathrm{PO}_{4}\right)$ with a constant temperature $\left(37^{\circ} \mathrm{C}\right)$ and a constant flow rate $(160 \mathrm{~mL} / \mathrm{min})$. Prior to the corrosion fatigue tests, the specimens' surface was grounded with 1000-grit green silicon carbide papers. Uniaxial tension tests were conducted along ED at room temperature with a cross-head speed of $0.03 \mathrm{~mm} / \mathrm{s}$. The specimen size was the same as the corrosion fatigue specimen.

The measured surface for the hydrogen evolution test was the longitudinal cross section of rods with dimensions of $20 \mathrm{~mm} \times 12 \mathrm{~mm}$, and other surfaces were protected with
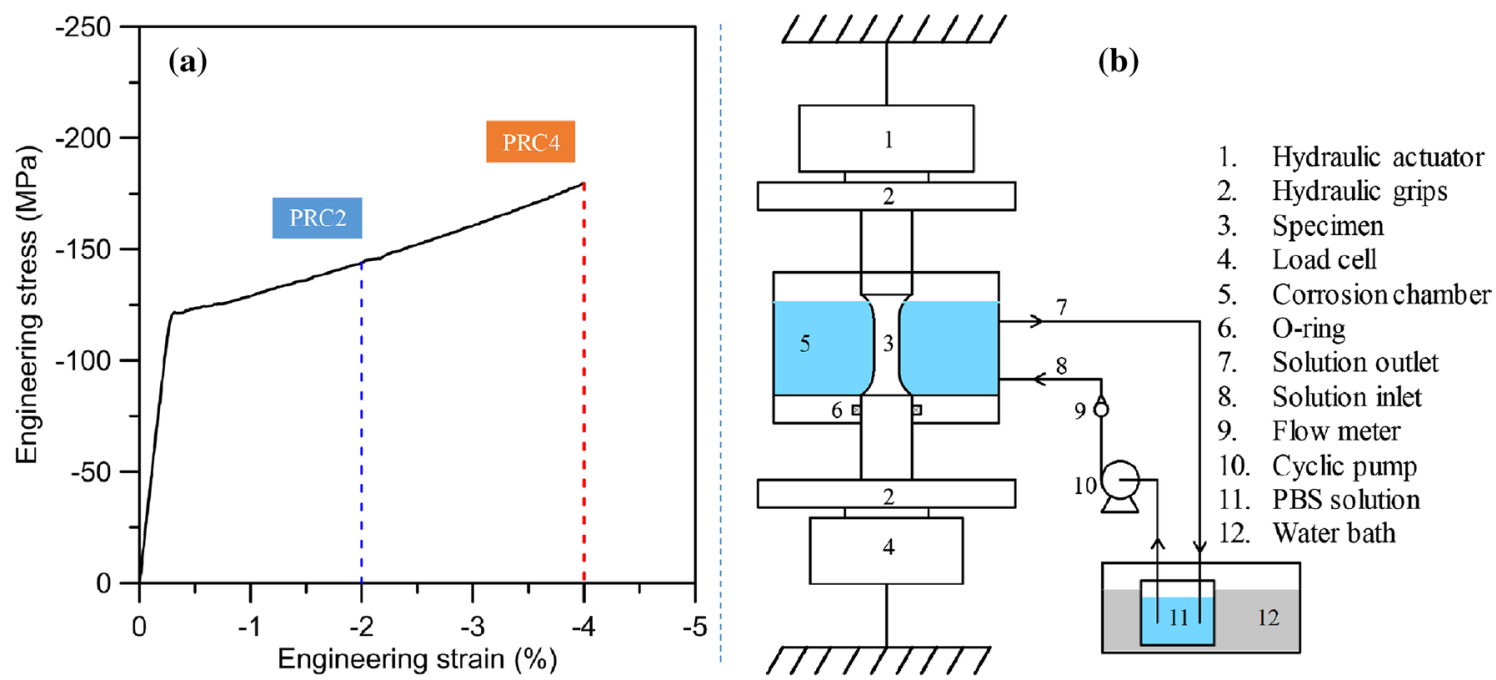

Fig. 1 Schematic of a pre-compressed sample processing, $\mathbf{b}$ corrosion fatigue experimental setup 
epoxy. Prior to the tests, the measured surface was also grounded with 1000-grit green silicon carbide papers. Then, the specimens were horizontally immersed in $600 \mathrm{~mL}$ $37^{\circ} \mathrm{C}$ PBS solution with saturated hydrogen for $48 \mathrm{~h}$, and the evolved hydrogen was collected in a burette above the corroded specimens and recorded.

A HITACHI S-3400 scanning electron microscope (SEM) equipped with an electron backscattering diffraction (EBSD) detector was employed to examine the evolution of the specimens' microstructure. The scanning step of EBSD test is $0.3 \mu \mathrm{m}$, and the scanning area is $300 \mu \mathrm{m} \times 300 \mu \mathrm{m}$. A KEYENCE VHX-900F optical microscope (OM) and HITACHI TDCLSU-1510 SEM were used to observe the corroded surfaces and fractures of specimens. The chromate acid solution
( $200 \mathrm{~g} / \mathrm{L} \mathrm{CrO}{ }_{3}$ and $10 \mathrm{~g} / \mathrm{L} \mathrm{AgNO}_{3}$ ) was prepared to remove the corrosion products of corroded specimens.

\section{Results}

\subsection{Microstructure Evolution and Mechanical Properties}

Figure 2 demonstrates the microstructure of the longitudinal cross section for the three investigated specimens observed by EBSD. As shown in Fig. 2a, the AR specimen shows a twin-free equiaxial grain structure with an average grain size of approximately $17 \mu \mathrm{m}$. According to the basal pole figure
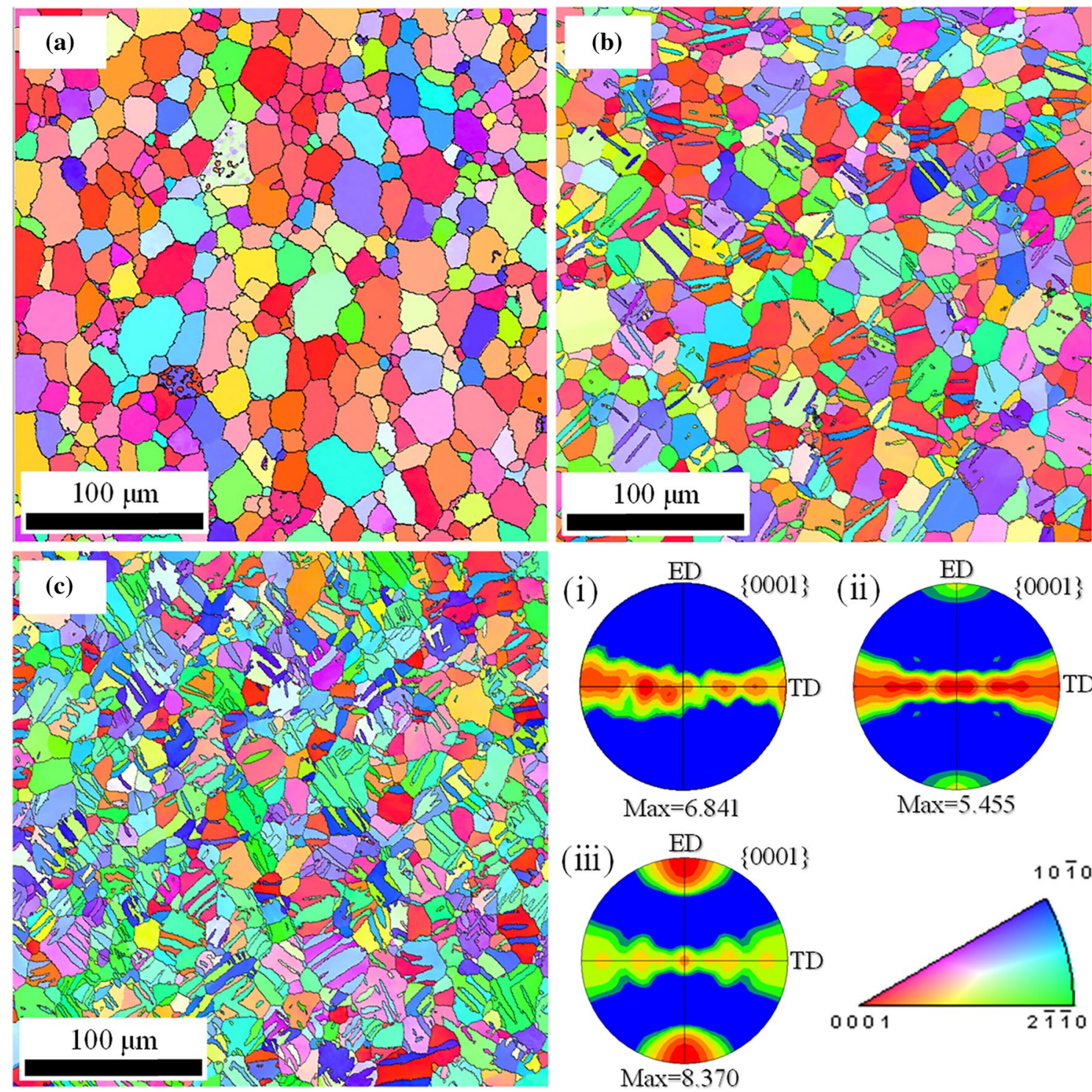

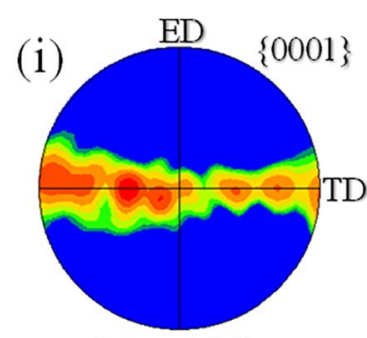

$\operatorname{Max}=6.841$

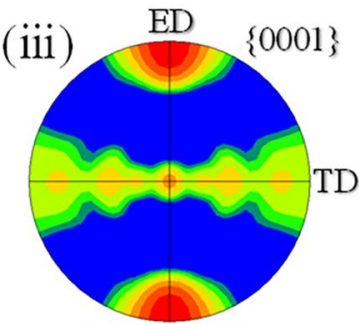

$\operatorname{Max}=8.370$
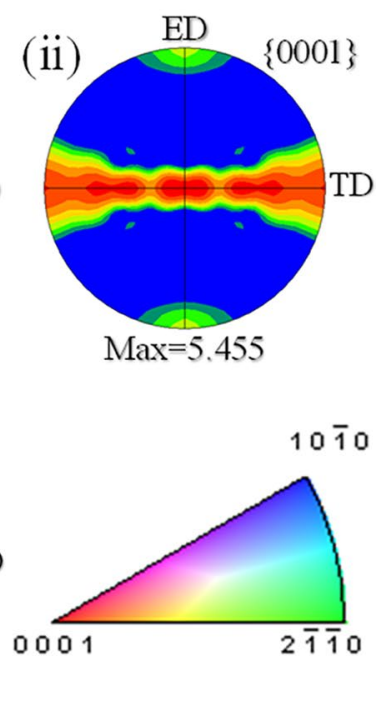

$10 \overline{10}$

\title{
(1)
}

\begin{abstract}
ined by EBSD: crystal orientation map in terms of the inverse pole fig-
\end{abstract} Fig. 2 Longitudinal cross section microstructure of the specimens examined by EBSD:
ures for a AR, b PRC2, $\mathbf{c}$ PRC4; corresponding pole figures for i AR, ii PRC2, iii PRC4 
shown in Fig. 2i, the AR specimen has a typical extrusion texture in extruded magnesium alloy rod where the $c$-axis of most grains are perpendicular to the ED. The extension twins are easily produced under compression loading along ED because of the perpendicular relationship between the loading direction and $c$-axis direction [25]. After 2\% pre-compression processing, many slim twins appear in the PRC2 specimen shown in Fig. 2b. Since the twinning dominates the plastic flow stage shown in Fig. 1a, further compression deformation can promote the production and growth of twins. As shown in Fig. 2c, a large number of coarse twins are produced in the PRC4 specimen, and these twins start to intersect or coalesce. By comparing the basal pole figure (Fig. 2i-iii) of three specimens, it can be seen that the twinning texture is strengthened and the basal texture is significantly weakened as the pre-compression strain increases.

Since the crystal orientation has a great influence on the corrosion results, it is essential to quantify the crystal orientation results of the longitudinal cross section. The basal plane-oriented grains on the longitudinal cross section are defined and marked for three investigated specimens in Fig. 3a, and those grains possess a deviation angle (absolute value $<30^{\circ}$ ) between the $c$-axis of grains and the normal direction of the test surface. In fact, it can be considered that the basal plane of the selected grain is approximately parallel to the longitudinal cross section. The area fraction of the basal plane-oriented grains in the whole test area has been calculated using ImageJ software, and the corresponding statistical results are shown in Fig. 3b. Because the $c$-axis orientation of the grains is random in the typical extrusion texture, the area fraction of basal plane oriented grains on the longitudinal cross section of the AR specimen is large $(\sim 32.5 \%)$. As the amount of pre-compression increases, the area fraction of basal plane oriented grains gradually decreases. Especially for the PRC4 specimen, the extension twins introduce a large number of prismatic planes into the longitudinal cross section and the area fraction of basal planes is reduced to about $14.1 \%$.

Figure 4 shows the uniaxial tensile curves of AR, PRC2 and PRC4 specimens. Table 1 summarizes the results of $\sigma_{\mathrm{y}}$ (yield strength), $\sigma_{\mathrm{u}}$ (ultimate strength) and $\delta$ (elongation).

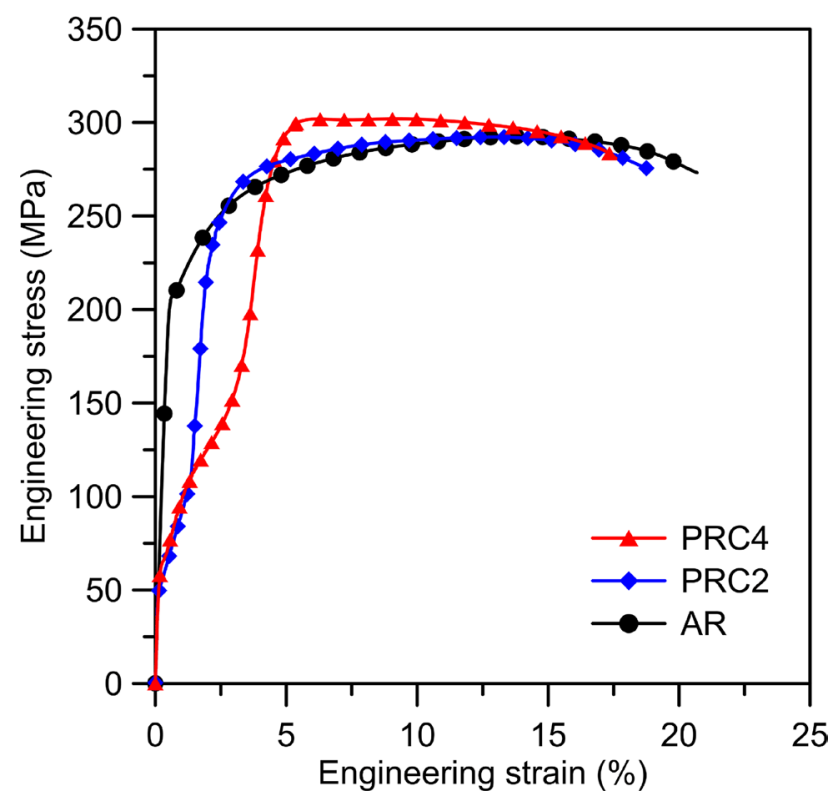

Fig. 4 Uniaxial tensile curves of AR, PRC2 and PRC4 specimens
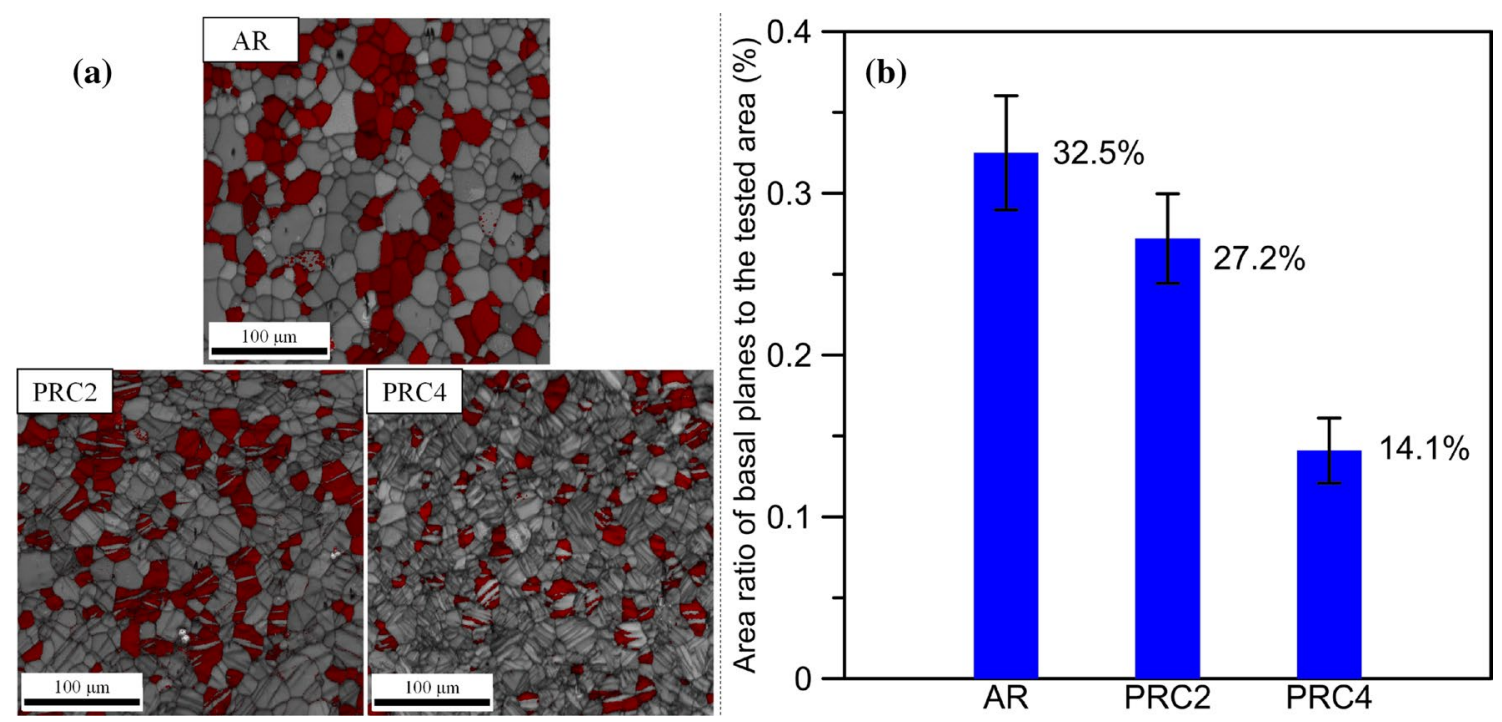

Fig. 3 a Distribution of basal plane-oriented grains (red region) on the longitudinal cross section of the three investigated specimens, $\mathbf{b}$ calculated area fraction of the basal plane-oriented grains in the whole test area 
Table 1 Tensile properties of the three investigated specimens: AR, PRC2, and PRC4

\begin{tabular}{lrll}
\hline Specimens & \multicolumn{1}{c}{$\sigma_{\mathrm{y}}(\mathrm{MPa})$} & $\sigma_{\mathrm{u}}(\mathrm{MPa})$ & $\delta(\%)$ \\
\hline AR & $205.2 \pm 4.1$ & $294.1 \pm 3.1$ & $20.7 \pm 0.3$ \\
PRC2 & $55.6 \pm 2.7$ & $294.0 \pm 2.5$ & $19.5 \pm 0.3$ \\
PRC4 & $68.0 \pm 2.1$ & $302.5 \pm 3.8$ & $17.6 \pm 0.2$ \\
\hline
\end{tabular}

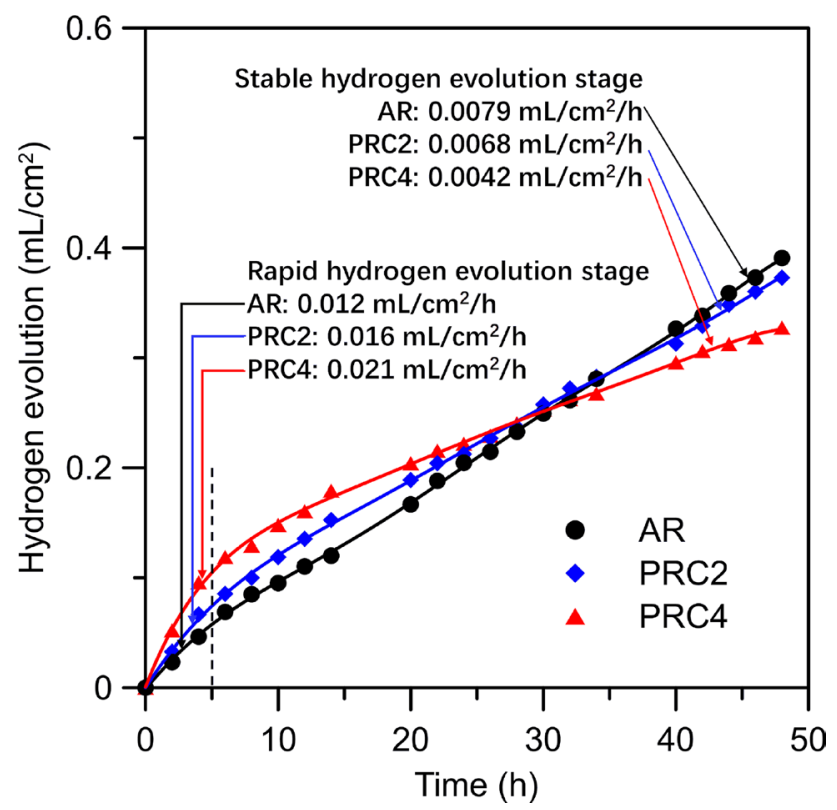

Fig. 5 Hydrogen evolution volume of three investigated specimens immersed in $37{ }^{\circ} \mathrm{C}$ PBS solution as a function of immersion time

Since initial twins of pre-compression specimens are favorable for de-twinning during tension along the ED, the PRC2 and PRC4 specimens show much lower yield strength than the AR specimen [26, 27]. Generally, more extension twins require higher stress to activate the de-twinning deformation [28]. Thus the PRC4 specimen shows larger yield strength than the PRC2 specimen. The dominant deformation mechanism transforms from de-twinning deformation to prismatic slip, resulting in a significant strain hardening behavior in the tension flow curve of the pre-compression specimens.

\subsection{Effects of Twinning Texture on Corrosion Performance}

The cathode reaction of the magnesium alloy in PSB solution is mainly a hydrogen evolution reaction. The results of hydrogen evolution rate can be used for judging the corrosion resistance of $\mathrm{Mg}$ alloys. Figure 5 shows the hydrogen evolution volume of three investigated specimens immersed in PBS solution as a function of immersion time. All the hydrogen evolution curves are divided into two stages by a dotted line: (1) rapid hydrogen evolution at the early stage and (2) stable and slow hydrogen evolution in subsequent stages. Ascencio et al. [29] reported that the early high hydrogen evolution rate was mainly ascribed to the formation of a porous corrosion layer. As the immersion time increased, the corrosion layer was thickened and became more protective. Then, the corrosive medium was separated from the substrate by the surface layer, leading to a stable and slow hydrogen evolution rate. Comparing the three curves, it can be seen that at the early stage of hydrogen evolution, PRC4 specimen has the fastest hydrogen evolution rate $\left(0.021 \mathrm{~mL} / \mathrm{cm}^{2} / \mathrm{h}\right)$, followed by the PRC2 $(0.016 \mathrm{~mL} /$ $\left.\mathrm{cm}^{2} / \mathrm{h}\right)$ and AR specimens $\left(0.012 \mathrm{~mL} / \mathrm{cm}^{2} / \mathrm{h}\right)$. After immersion for about $5 \mathrm{~h}$, the hydrogen evolution rate of PRC4 specimen $\left(0.0042 \mathrm{~mL} / \mathrm{cm}^{2} / \mathrm{h}\right)$ decreases by about $80.0 \%$. For the PRC2 and AR specimens, the hydrogen evolution rate $\left(0.0068\right.$ and $\left.0.0079 \mathrm{~mL} / \mathrm{cm}^{2} / \mathrm{h}\right)$ decreases by only $57.5 \%$ and $34.2 \%$, respectively. This result indicates that the surface film of PRC4 specimen owns the best protection, followed by the PRC2 specimen, and the AR specimen is the worst.

After the hydrogen evolution test, the corrosion product layer and corroded surfaces (without corrosion products) are observed by SEM, and the corresponding results are shown in Fig. 6. Comparing to Fig. 6a, c and e, as the precompression strain increases, the corrosion product layer becomes more compact and uniform, which further confirms that the twinning texture enhances the protective effect of the corrosion film. Moreover, due to lower twin boundary energy, twins do not cause the formation of micro-cracks of surface film [11], which is in agreement with the observed results shown in Fig. 6e. After the removal of corrosion products, the corroded surface (without corrosion products) of the three specimens displays different features. As shown in Fig. 6b, partially corroded grains of the AR specimen have a canyon-like corrosion feature and other grains show a general corrosion feature. Compared to the AR specimen, the number of grains with canyon-like corrosion features of the PRC2 specimen shown in Fig. 6d reduces, and slim twins appear in some grains. However, for the PRC4 specimen shown in Fig. 6f, only coarse twins are observed and no canyon-like corrosion features can be found.

\subsection{Effects of Twinning Texture on Corrosion Fatigue Behavior}

\subsubsection{Effects of Twinning Texture on Cyclic Response}

Figure 7 a demonstrates the cyclic strain amplitude responses of three investigated specimens during corrosion fatigue. Figure $7 \mathrm{~b}$ and $\mathrm{c}$ displays the stress-strain hysteresis loops of 100th cycle under $120 \mathrm{MPa}$ and $65 \mathrm{MPa}$ stress amplitude, respectively. In order to compare the differences of the hysteresis loops, the average value 


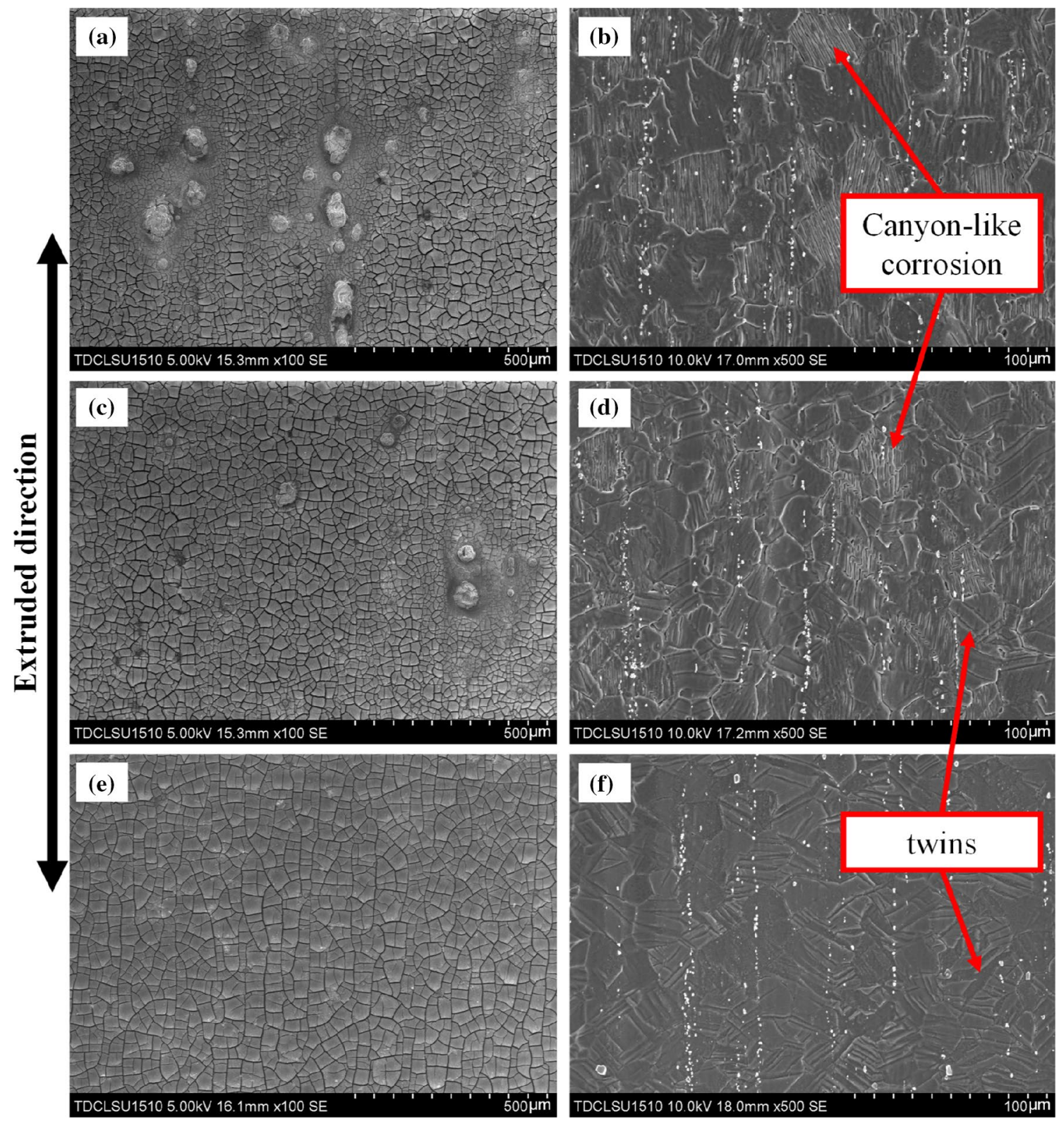

Fig. 6 Corrosion product layer of three investigated specimens after hydrogen evolution tests: a AR, c PRC2, e PRC4, and the corresponding corrosion surface (without corrosion products): b AR, d PRC2, f PRC4

of the strain is located at the zero point of the $X$ coordinate system. Since no extensometer is used, the strain (the ratio of machine displacement to gauge length) is an apparent value. For the AR specimens, the cyclic strain amplitude in Fig. 7a shows cyclic stability feature under all the stress amplitude. Both at 120 and $65 \mathrm{MPa}$ stress amplitude shown in Fig. $7 \mathrm{~b}$ and c, the shape of hysteresis loops of the AR specimen is a straight line. It indicates that elastic deformation dominates the cyclic responses of the AR specimens in the stress amplitude range of 65 to $120 \mathrm{MPa}$. Only localized plastic deformation occurs during the cyclic loading [30].
For the pre-compression specimens, their cyclic strain amplitude is obviously higher than those of the AR specimens under $120 \mathrm{MPa}$ stress amplitude, due to the involvement of twinning and de-twinning deformation. Under the same stress amplitude, twinning and de-twinning deformation can produce greater plastic strains than the elastic deformation. Therefore, as shown in Fig. 7b, pre-compression specimens display larger hysteresis loops than the AR specimen. Moreover, the continuous consumption of pre-existed twins during the cycle will lead to the cyclic hardening behaviors at $120 \mathrm{MPa}$ stress amplitude shown in Fig. 7a. As the stress amplitude decreases, the number of twins involved 

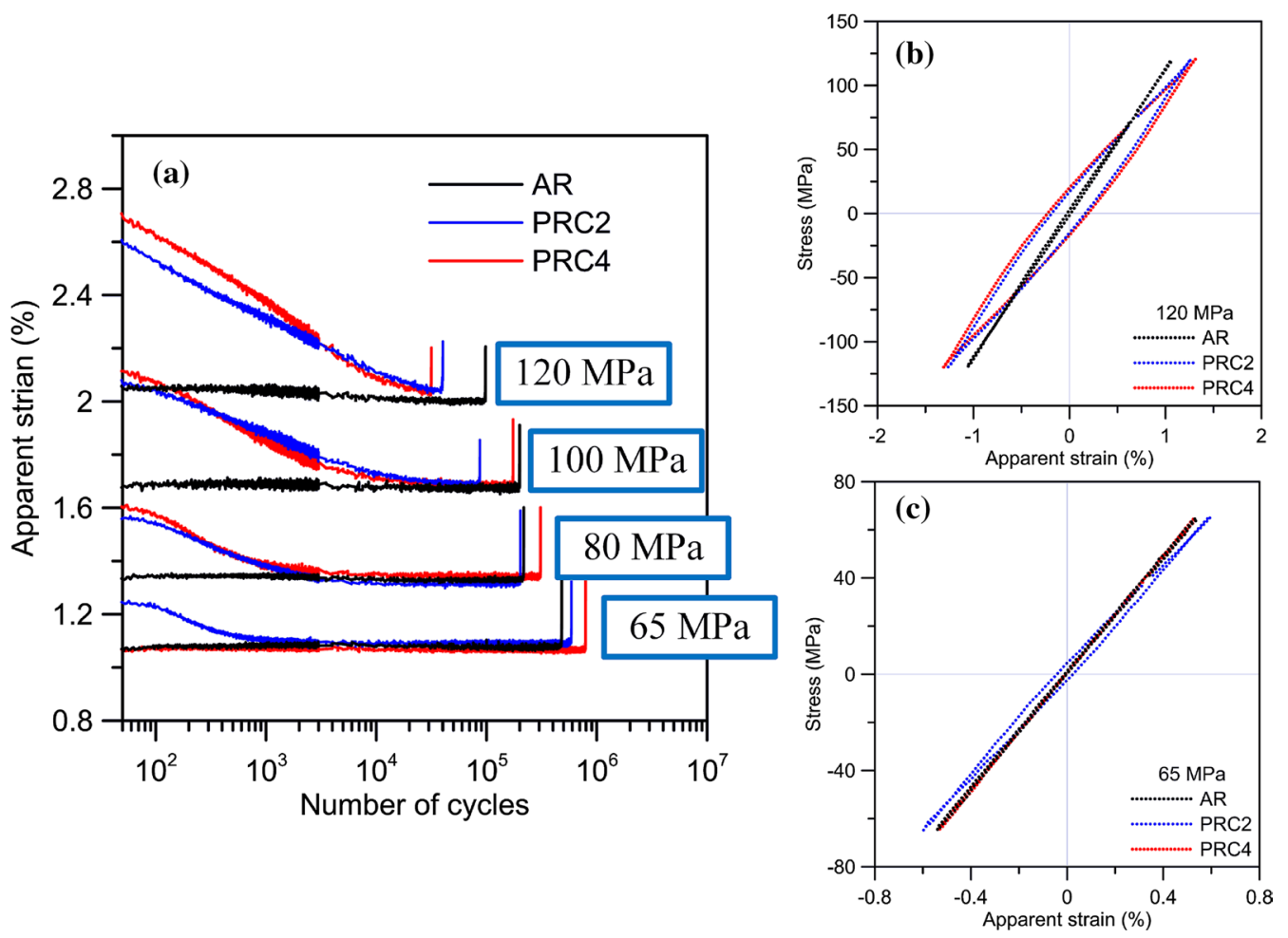

Fig. 7 a Variations in the strain responses with the number of cycles under different stress amplitudes; b stress-strain hysteresis loops of the 100th cycle under $120 \mathrm{MPa}$ stress amplitudes; $\mathbf{c}$ under $65 \mathrm{MPa}$ stress amplitudes

in the cyclic deformation gradually decreases and the precompression specimens show cyclic stability feature. When the stress amplitude drops to $65 \mathrm{MPa}$ shown in Fig. 7a, the PRC4 specimen shows cyclic stability throughout the whole life. Besides, the cyclic hardening process of PRC2 specimen only accounts for about $0.17 \%$ of the entire fatigue life. At the same time, as shown in Fig. 7c, the hysteresis loop of the PRC4 specimen is almost identical to that of the AR specimen, showing a linear characteristic. And the hysteresis loop of the PRC2 specimen is also close to a straight line, which only displays a slight difference from that of the AR specimen. It suggests that under $65 \mathrm{MPa}$ stress amplitude, the contribution of extension twins to cyclic deformation is almost negligible.

\subsubsection{Effects of Twinning Texture on Corrosion Fatigue Lives}

Figure 8 shows the variations of the corrosion fatigue lives under the different stress amplitudes for three investigated specimens. The life differences between the AR specimen and the pre-compression specimens gradually reduce as the stress amplitude decreases. When the stress amplitude drops to $65 \mathrm{MPa}$, the lives of the pre-compression specimens exceed that of AR specimens. In addition, the lives of PRC4 specimens are higher than those of the PRC2 specimens at

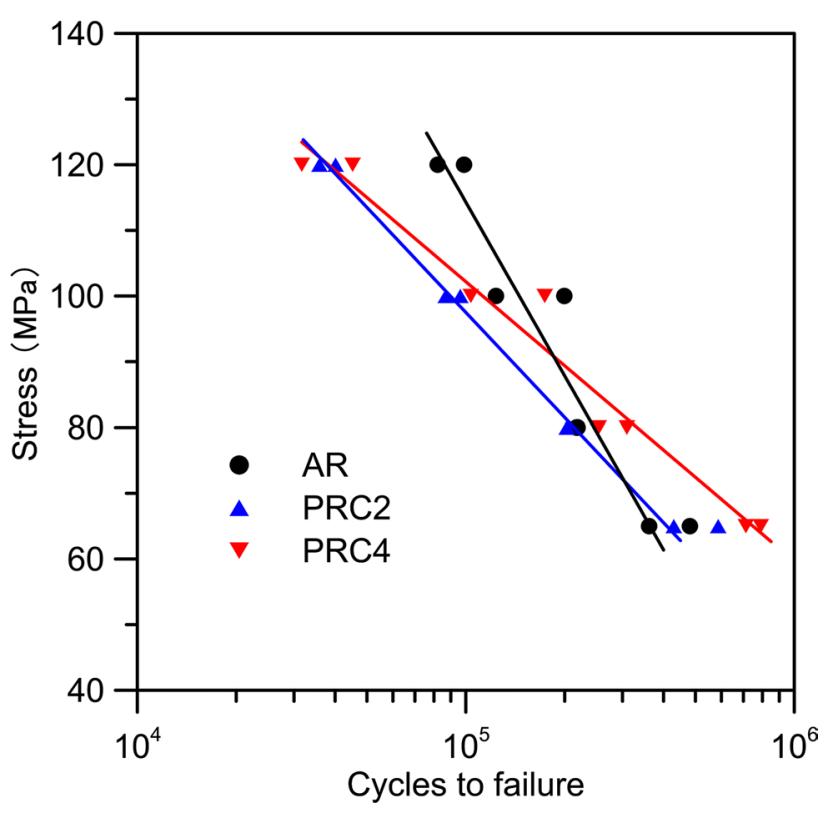

Fig. 8 Variations of the corrosion fatigue lives under the different stress amplitudes for three investigated specimens

the same stress amplitude, and the life differences between the two specimens gradually increase as the stress amplitude decreases. 


\subsubsection{Corrosion Fatigue Under Low Stress Amplitude}

Since the low stress amplitude ensures enough time for interaction between corrosion and cyclic loading, it is critical to investigate the corrosion fatigue behavior under low stress amplitude. The variations of the corrosion fatigue lives with the pre-compression deformation strain under $65 \mathrm{MPa}$ stress amplitude are shown in Fig. 9a. The corroded surfaces (without corrosion products) under $65 \mathrm{MPa}$ stress amplitude are observed by OM and shown in Fig. 9b-d. First, the surface of the AR specimen shown in Fig. 9b has a large number of secondary cracks, which are perpendicular to the ED. For PRC2 specimens shown in Fig. 9c, the secondary cracks still exist, but they become shallow. However, for the PRC4 specimen shown in Fig. 9d, almost no severe secondary cracks can be found, and a uniform corrosion surface is formed.

Fracture morphology under the $65 \mathrm{MPa}$ stress amplitude is also observed by SEM and shown in Fig. 10. The crack nucleation region is highlighted by a rectangular mark and shown at a high magnification. As shown in Fig. 10a, the AR specimens show a multi-point cracking and step-like fracture morphology. In addition, no foreign particles such as inclusions, second-phase particles, or pitting corrosion defects are observed in the crack nucleation region, and the edge of the crack nucleation region is also smooth (Fig. 10b). Both of them indicate that the fracture of AR specimen indeed initiates from the secondary crack of surface. For the PRC2 specimen, the fracture morphology in Fig. 10c and the crack nucleation region in Fig. 10d show similar features as those found in the AR specimen, i.e. multi-point cracking and smooth crack nucleation region edge. However, for the PRC4 specimen shown in Fig. 10e, the crack tends to initiate from one point and propagate in one plane along the radiation direction, which is commonly observed in smooth specimens tested in air [18]. In addition, an inclusion defect shown in Fig. 10f is found at edge of the crack nucleation region. It indicates that

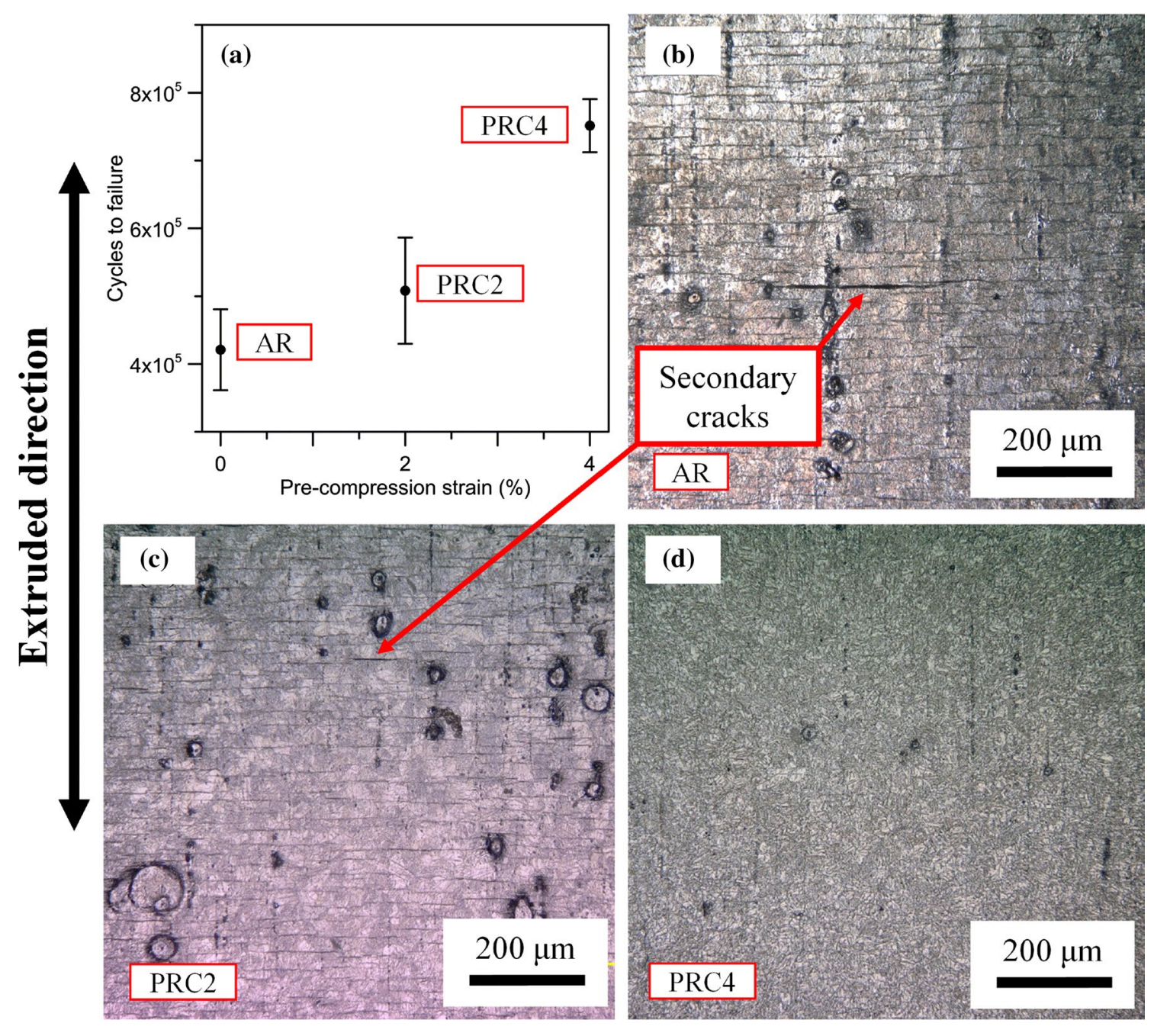

Fig. 9 a Variations of the corrosion fatigue lives with the pre-compression deformation strain under 65 MPa stress amplitude and corresponding surfaces after corrosion fatigue tests: b AR specimen, $\mathbf{c}$ PRC2 specimen, $\mathbf{d}$ PRC4 specimen 

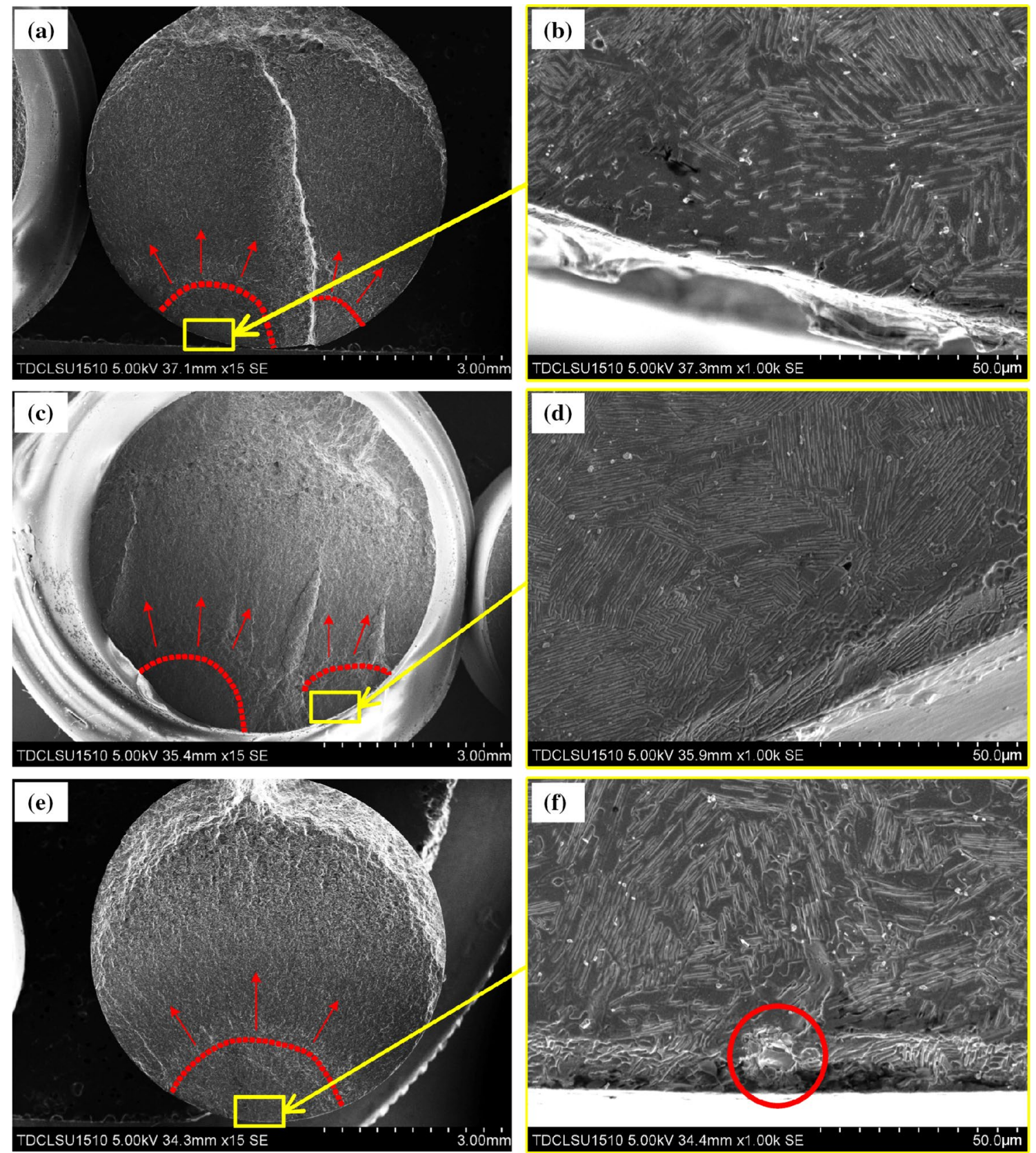

Fig. 10 Fracture images (without corrosion products) after corrosion fatigue tests at $65 \mathrm{MPa}$ for a AR specimen, $\mathbf{c}$ PRC2 specimen, e PRC4 specimen, and the corresponding crack nucleation region for $\mathbf{b}$ AR specimen, $\mathbf{d}$ PRC2 specimen, $\mathbf{f}$ PRC4 specimen

the fracture of PRC4 specimen initiates from inclusion defect rather than the secondary crack of surface.

\section{Discussion}

\subsection{Effects of Twinning Texture on Corrosion Performance}

In general, twins play a dual role in the corrosion behavior of Mg alloys: (1) accelerate the dissolution tendency of Mg matrix and (2) facilitate the formation of surface oxide film [12]. In the current study, since the former dominates the reaction at the early stage of immersion, the pre-compression specimens show a higher hydrogen evolution rate than the AR specimen. With the increase of immersion time, the formation of compact surface film provides better protection for the matrix. Especially for PRC4 specimens with a large number of twins, the corrosion resistance in the second stage of hydrogen evolution is significantly improved. 
Due to localized galvanic corrosion of basal and nonbasal planes on longitudinal cross section, AR specimen forms inhomogeneous corrosion product layer shown in Fig. 6a, which is consistent with the results of Wang et al. [16]. And the canyon-like corrosion feature shown in Fig. 6b is evidence left by localized galvanic corrosion [31]. For the AR specimen, the surface energy difference between basal planes and non-basal planes is the largest. After pre-compression treatment, many basal planes are removed from the longitudinal cross section owing to the introduction of twinning texture (shown in Fig. 3). Then the uniformity of surface energy of longitudinal cross section is improved, which is very beneficial to the formation of uniform and compact oxide film [11, 12]. Especially for the PRC4 specimen, the area fraction of basal planes obviously reduces, which improves the uniformity of compactness the surface film shown in Fig. 6e.

\subsection{Effects of Twinning Texture on Corrosion Fatigue}

Since corrosion is a time-dependent phenomenon, high stress amplitude hardly provides sufficient time for corrosion and facilitates the synergistic effect between corrosion and mechanical loading. In this case, the differences in mechanical damage caused by twinning texture dominate the corrosion fatigue life. It can be seen from Sect. 3.3.1 that pre-existed twins significantly affect the cyclic response of pre-compression specimens under high stress amplitude, resulting in larger plastic deformation and hysteresis loops area than AR specimens. A larger hysteresis loops area can cause more energy dissipation during each cycle [32]. That means pre-compression specimens suffer much greater mechanical damage than the AR specimen under high stress amplitude. Besides, the twining and de-twining deformation can form residual twins, which deteriorate the materials' fatigue life [26, 33 , 34]. In addition, the hydrogen atoms precipitated from the cathode reaction will also affect the results of corrosion fatigue, although chemical damage is not the main factor at high stress amplitude. Solute hydrogen atoms are easily trapped at the dislocation cores, grain boundaries, and crack tips. The hydrogen atoms trapped at the crack tip can facilitate the dislocation activity and thus accelerate the crack growth rate of $\mathrm{Mg}$ alloys [35, 36]. According to the results of hydrogen evolution shown in Fig. 5, the hydrogen evolution rate of AR specimen is lower than that of pre-compression specimen during the early stage of immersion. This allows the crack tip of the pre-compression specimen to absorb more hydrogen atoms and thus exacerbate hydrogen embrittlement. Under the combined effect of mechanical and chemical damage at $120 \mathrm{MPa}$ stress amplitude, the pre-compression specimens display lower corrosion fatigue resistance than the AR specimen.

Under $65 \mathrm{MPa}$ stress amplitude, the de-twinning process is hardly involved in the cyclic deformation. Three investigated specimens display similar cyclic displacement amplitude response and hysteresis loop shown in Fig. 7a and c. In this case, the differences in the mechanical damage can be neglected. However, the low stress amplitude can provide adequate time for corrosion process, and thus, the chemical damage difference becomes the main factor determining the corrosion fatigue lives. It can be seen from Fig. 5 that after immersing for a long time, the hydrogen evolution rate of PRC4 specimen obviously lower that of AR specimen. As a result, the effect of hydrogen embrittlement on AR samples is more serious, which can be confirmed by the severe secondary cracks on the surface shown in Fig. 9b. The secondary crack on the surface can be taken as an evidence of hydrogen atoms entering into the matrix. The schematic illustration of forming mechanism of secondary cracks on the surface of AR specimen is shown in Fig. 11a. The incomplete surface corrosion film provides a large number of channels for hydrogen atoms to diffuse into matrix. Even under the cyclic elastic deformation, localized dislocation slip can also be activated. The dislocations promote hydrogen atoms to enter the matrix; meanwhile, hydrogen atoms trapped in dislocation cores can also facilitate dislocation activity and exacerbate localized plastic strain [30, 36, 37]. Localized stress concentration caused by localized plastic strain will accelerate the cracking of magnesium alloys'

(a)
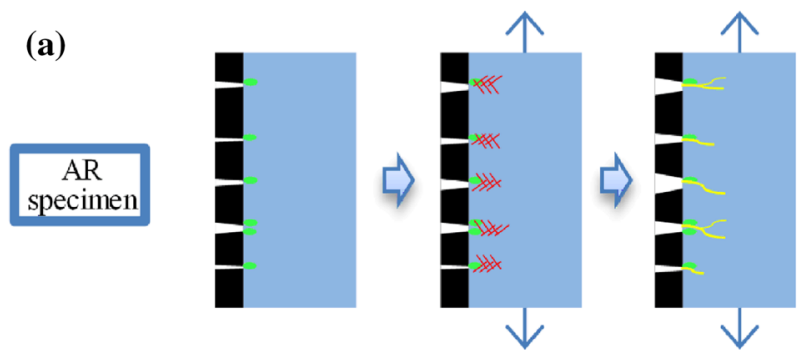

(b)

PRC4 specimen
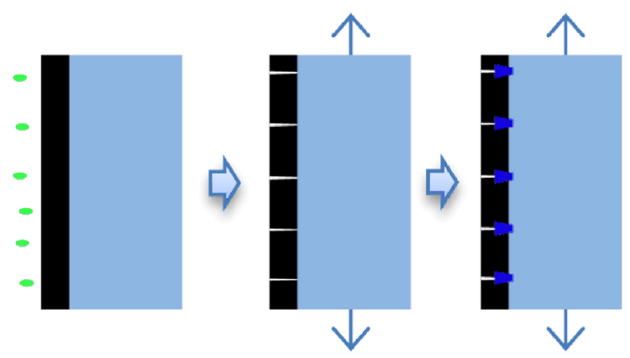

Matrix

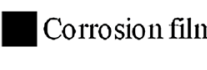

Hydrogen

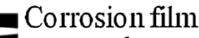
crack

$\Uparrow$ Loading /// Dislocations

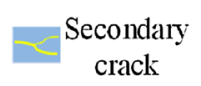

Re-passivation corrosion film

Fig. 11 Schematic illustration of forming mechanism of corrosion fatigue surface: a AR specimen, b PRC4 specimen 
surface, thereby forming secondary cracks. A large number of secondary cracks will lead to multi-point cracking (Fig. 10a) under cyclic loading. This cracking mode would greatly reduce the corrosion fatigue lives of AR specimens. However, for PRC4 specimens shown in Fig. 11b, the compact and complete corrosion film prevents hydrogen atoms from contacting $\mathrm{Mg}$ matrix. Even if corrosion film would be slightly damaged under the cyclic loading, the re-passivation of the matrix can quickly heal surface corrosion film and provide a good protection to the matrix. On the other hand, the lower hydrogen evolution rate can reduce the hydrogen concentration on the surface. The driving force of magnesium matrix to adsorb and trap hydrogen atoms is weakened, thereby suppressing the effects of hydrogen embrittlement. As a result, only uniform and shallow corrosion marks are left on the surface of PRC4 specimens (Fig. 9d), which is very beneficial for the corrosion fatigue resistance of PRC4 specimens.

\section{Conclusions}

AM60 Mg alloy extruded rods were compressed to different strains at room temperature. The influence of twinning texture on the corrosion performance and corrosion fatigue resistance was investigated and the following conclusions were drawn:

1. The twinning texture removes basal planes on the longitudinal cross section and increases the uniformity of surface energy, which is beneficial to the formation of compact and complete surface film. The integrity of surface film dominates the second stage of hydrogen evolution, thereby improving the corrosion resistance of current stage.

2. Under high stress amplitude, pre-compression specimens display large cyclic plastic deformation due to the involvement of twinning and de-twinning deformation. In addition, the rapid hydrogen evolution rate exacerbates hydrogen embrittlement, thereby resulting in low corrosion fatigue resistance. The effects of extension twins on deformation are gradually weakened as the stress amplitude decreases.

3. Under low stress amplitude, higher hydrogen evolution rate and the secondary cracks caused by hydrogen embrittlement significantly deteriorate the corrosion fatigue resistance of AR specimens. The twinning texture of PRC4 specimens reduces the rate of hydrogen evolution and suppresses the tendency of hydrogen induced cracking, thereby improving corrosion fatigue resistance.

4. Sufficient pre-compression deformation is expected to be a potential way to enhance the corrosion fatigue resist- ance of $\mathrm{Mg}$ alloy rods in low stress amplitude regimes where biological implants often service. In future work, the effect of twinning textures with different orientation on corrosion resistance will be systematically studied to obtain optimized twinning textures.

Acknowledgements This study was sponsored by the National Natural Science Foundation of China (No. 51571150) and the Tianjin Natural Science Foundation (No. 14JCYBJC16900). We would also like to thank Professor Xu Chen for his guidance, and Dr. Shengkun Wang and Dr. Zheng Liu for their help.

\section{References}

[1] J.H. Zhang, S.J. Liu, R.Z. Wu, L.G. Hou, M.L. Zhang, J. Manag. Alloys 6, 277 (2018)

[2] Y.X. Meng, H. Gao, Y.Z. Yan, L.L. Gao, Mater. Today Commun. 24, 101159 (2020)

[3] F. Zhong, H.J. Wu, Y.L. Jiao, R.Z. Wu, J.H. Zhang, L.G. Hou, M.L. Zhang, J. Mater. Sci. Technol. 39, 124 (2020)

[4] R.K. Singh Raman, S. Jafari, S.E. Harandi, Eng. Fract. Mech. 137, 97 (2015)

[5] H. Gao, W.B. Ye, Z. Zhang, L.L. Gao, J. Mater. Res. 32, 2143 (2017)

[6] H. Gao, M. Zhang, J. Zhao, L. Gao, M. Li, Mater. Sci. Eng. C 63, 450 (2016)

[7] J.H. Wang, H. Gao, L.L. Gao, Y. Cui, Z.Y. Song, J. Mech. Behav. Biomed. Mater. 88, 176 (2018)

[8] H. Gao, J.H. Wang, F. Li, L.L. Gao, Z. Zhang, Mater. Sci. Eng. C 89, 295 (2018)

[9] S.H. Park, Mater. Sci. Eng. A 680, 214 (2017)

[10] S.G. Hong, S.H. Park, C.S. Lee, Acta Mater. 58, 5873 (2010)

[11] G.D. Zou, Q.M. Peng, Y.N. Wang, B.Z. Liu, J. Alloys Compd. 618, 44 (2015)

[12] J.H. Liu, E.H. Han, Y.W. Song, D.Y. Shan, J. Alloys Compd. 757, 356 (2018)

[13] B.Q. Fu, W. Liu, Z.L. Li, Appl. Surf. Sci. 255, 9348 (2009)

[14] M. Liu, D. Qiu, M.C. Zhao, G.L. Song, A. Atrens, Scr. Mater. 58, 421 (2008)

[15] B.J. Wang, D.K. Xu, J.H. Dong, W. Ke, J. Mater. Res. Technol. 32, 646 (2016)

[16] B.J. Wang, D.K. Xu, J.H. Dong, W. Ke, Scr. Mater. 88, 5 (2014)

[17] L. Choudhary, R.K. Raman, Acta Biomater. 8, 916 (2012)

[18] X.N. Gu, W.R. Zhou, Y.F. Zheng, Y. Cheng, S.C. Wei, S.P. Zhong, T.F. Xi, L.J. Chen, Acta Biomater. 6, 4605 (2010)

[19] B.J. Wang, D.K. Xu, S.D. Wang, L.Y. Sheng, R.C. Zeng, E.H. Han, Int. J. Fatigue 120, 46 (2019)

[20] S. Jafari, R.K. Singh Raman, C.H.J. Davies, Eng. Fract. Mech. 137, 2 (2015)

[21] A.M. Panindre, V.S. Raja, M. Ajay Krishnan, Corros. Sci. 115, 8 (2017)

[22] B.J. Wang, J.Y. Luan, D.K. Xu, J. Sun, C.Q. Li, E.H. Han, Acta Metall. Sin. (Engl. Lett.) 32, 1 (2018)

[23] M.R. Barnett, Z. Keshavarz, A.G. Beer, D. Atwell, Acta Mater. 52, 5093 (2004)

[24] T.T. Liu, Q.S. Yang, N. Guo, Y. Lu, B. Song, J. Magnes. Alloys 8, 66 (2020)

[25] Y.C. Lin, Z.H. Liu, X.M. Chen, J. Chen, Mater. Sci. Eng. A 573, 234 (2013)

[26] W. Wu, K. An, J. Alloys Compd. 656, 539 (2016)

[27] Y. Xin, X. Zhou, L. Lv, Q. Liu, Mater. Sci. Eng. A 606, 81 (2014) 
[28] S.H. Park, S.-G. Hong, C.S. Lee, Scr. Mater. 62, 666 (2010)

[29] M. Ascencio, M. Pekguleryuz, S. Omanovic, Corros. Sci. 87, 489 (2014)

[30] B.J. Wang, D.K. Xu, S.D. Wang, E.H. Han, Front. Mech. Eng. 14, 113 (2017)

[31] S. Pawar, T.J.A. Slater, T.L. Burnett, X. Zhou, G.M. Scamans, Z. Fan, G.E. Thompson, P.J. Withers, Acta Mater. 133, 90 (2017)

[32] Y.C. Lin, X.M. Chen, Z.H. Liu, J. Chen, Int. J. Fatigue 48, 122 (2013)
[33] J.Q. Hu, H. Gao, Y.X. Meng, Z. Zhang, L.L. Gao, Mater. Sci. Eng. A 726, 215 (2018)

[34] X.M. Chen, Y.C. Lin, J. Chen, J. Alloys Compd. 579, 540 (2013)

[35] T. Kakiuchi, Y. Uematsu, Y. Hatano, M. Nakajima, Y. Nakamura, T. Taniguchi, Eng. Fract. Mech. 137, 88 (2015)

[36] S. Lynch, Stress Corros. Crack. 30, 90 (2012)

[37] N. Winzer, A. Atrens, G. Song, E. Ghali, W. Dietzel, K.U. Kainer, N. Hort, C. Blawert, Adv. Eng. Mater. 7, 659 (2005) 